\title{
Structural reforms and the potential effects on the Italian economy is
}

\author{
Barbara Annicchiarico $^{\mathrm{a}, *}$, Fabio Di Dio ${ }^{\mathrm{b}}$, Francesco Felici ${ }^{\mathrm{c}}$ \\ a Department of Economics, University of Rome "Tor Vergata", Via Columbia 2, 00133 Roma, Italy \\ b Consip S.p.A., Macroeconomic Modelling Unit, Italy \\ ${ }^{\mathrm{c}}$ Italian Ministry of Economy and Finance, Department of the Treasury, Economic and Financial Analysis and \\ Planning Directorate, Italy
}

Received 14 November 2011; received in revised form 23 March 2012; accepted 26 March 2012

\begin{abstract}
Since the second half of 2011, after a period of prolonged low growth, Italy has found itself at the center of a severe economic crisis. Concerns about the sustainability of its debt burden, along with gloomy growth prospects, have pushed up the cost of government borrowing, exacerbating current economic conditions. At the moment Italy is facing two mounting economic challenges: (i) achieve a rapid fiscal consolidation to restore financial market confidence; (ii) implement structural reforms to strengthen medium-term growth prospects. Using the European Commission's model QUEST III with R\&D, adapted to Italy, we quantify the potential effects of a set of interventions inspired to the reform packages currently being undertaken or under discussion and consider different levels of policy effort. Results show that reforms are likely to bring about sizable gains in output, consumption, employment and net foreign assets position and that most of these gains derive from labor market reforms. However, the fiscal austerity plan is likely to severely mitigate
\end{abstract}

\footnotetext{
is We are very grateful to Werner Roeger, Janos Varga and Jan in't Veld for sharing with us many invaluable insights about their model, QUEST III. We gratefully acknowledge Antonio Maria Costa, the editor, and the anonymous referees for their helpful comments. We are also indebted to Alexandr Hobza, Gilles Mourre and the participants to the LIME Modeling Workshop 2010 and to the EcoMod2011 conference for useful discussions and suggestions on a earlier version of this paper. The usual disclaimer applies. The views expressed herein are those of the authors and not necessarily reflect those of the Italian Ministry of Economy and Finance.

* Corresponding author. Tel.: +390672595731.

E-mail addresses: barbara.annicchiarico@uniroma2.it (B. Annicchiarico), fabio.didio@tesoro.it (F. Di Dio), francesco.felici@tesoro.it (F. Felici).
} 
the positive effects of the interventions, especially during the earlier phases of the reform process. Most of these losses accrue to liquidity-constraint households who would experience a drop in consumption. (C) 2012 Society for Policy Modeling. Published by Elsevier Inc. All rights reserved.

JEL classification: E10; E60; E47

Keywords: Structural reforms; Fiscal consolidation; Simulation analysis; Italy

\section{Introduction}

In recent months Italy has found itself in the middle of a confidence crisis overwhelming the Euro area as a whole. Notably, since the 2008 crisis massive public interventions along with reduced fiscal revenues and a severe economic downturn have deteriorated the public balance sheets in many advanced economies, so that the crisis itself entered a new phase of sovereign debt problems and lack of confidence. In the Euro area the sovereign debt crisis started in Greece, then spread to Ireland and Portugal, and more recently to Spain and Italy. ${ }^{1}$ The problems in Italy originated from a prolonged period of low growth, a high public debt burden and poor growth prospects. Since August 2011 fears that it might default on its debt have severely increased the cost of government borrowing, further deteriorating the economic conditions. These recent developments have called for the need of a tight fiscal consolidation package, necessary to restore market confidence and improve the public sector balance sheet, followed by a wide-ranging economic reform process to enhance growth prospects.

In this paper, using the QUEST III with R\&D model adapted to Italy (see Roeger, Varga, \& in't Veld, 2008), we will explore the potential effects of a set of policy interventions inspired to the reform packages currently being undertaken or on the table that aim at promoting those favorable conditions necessary to revive the Italian economy. In particular, we construct different reform scenarios, consider different levels of policy effort and account for some of the provisions in the spirit of the already passed budgetary consolidation packages. ${ }^{2}$

QUEST III with R\&D is an extension of the original dynamic general equilibrium (DGE) model for quantitative policy analysis developed by the Directorate General for Economic and Financial Affairs (DG ECFIN) of the European Commission (see Ratto, Roeger, \& in't Veld, 2009). In particular, in our simulation exercise we will use the version already employed by the Commission in several multi-country analyses of structural reforms (e.g. D'Auria, Pagano, Ratto, \& Varga, 2009). To the best of our knowledge this paper represents one of first attempts to analyze the implications of a comprehensive and ambitious reform package on the Italian economy by employing a dynamic general equilibrium model. ${ }^{3}$

The literature studying the potential macroeconomic effects of structural reforms is quite large and a complete survey is beyond the scope of this paper. Hence, we will only briefly refer

\footnotetext{
1 On the current EMU crisis, see Issing (2011).

2 Decree Laws nos.98/2011, 138/2011 and 201/2011 (the so called "Save Italy" decree) include an austerity package over three years with the aim of balancing the budget already in 2013. The overall fiscal adjustment now amounts to about 80 billion euros, the equivalent of around $6 \%$ of the GDP.

${ }^{3}$ Forni, Gerali, and Pisani (2010a) study the effects of increasing competition in the services sector in Italy, employing a two-region currency union DGE model. In an early version of this paper, Annicchiarico, Di Dio, and Felici, (2011) quantify the economic impact of several reforms in the spirit of the Europe 2020 strategy.
} 
to a few of those studies evaluating the effects of structural reforms in the context of DGE models. Most of these models integrate typical New Keynesian elements (such as imperfect competition and nominal rigidities) into a general equilibrium framework (e.g. Smets \& Wouters, 2003, 2007; Galí \& Gertler, 2007; Woodford, 2003, among others). This modeling approach represents a useful tool for macroeconomic evaluation and policy analysis in an environment with several market imperfections, capturing the dynamic linkages between the main macroeconomic variables, the interactions between rigidities on labor and product markets and, as a consequence, the effects on economic growth in a coherent way. Yet, it is not until relatively recently that DGE models have been used to this purpose. ${ }^{4}$ First of all, the European Commission has produced several contributions investigating the effects of a battery of policy interventions on the EU economy and/or single member states using QUEST III with R\&D (e.g. Roeger et al., 2008; D'Auria et al., 2009), studying the implications of the implementation of reform packages in the spirit of the Europe 2020 strategy on the EU (see Hobza \& Mourre, 2010), concentrating on reform areas fostering innovation and knowledge creation in the EU, consistently with the Lisbon Agenda (see Arpaia et al., 2007, Roeger, Varga, \& in't Veld, 2009), exploring the growth potential stemming from comprehensive environmental and innovation policy interventions (see Conte, Labat, Varga, \& Zarnic, 2010) and analyzing the performance of different fiscal policy rules under alternative scenarios of sluggish growth (see Breuss \& Roeger, 2005). In variants of the International Monetary Fund's global economy model (GEM) Bayoumi, Laxton, and Pesenti (2004) study the impact of introducing pro-competitive reforms in the overall euro area, while Everaert and Schule (2006) focus on national-level reforms, considering a large economy, France, and a small one, Belgium. Using the Euro area and global economy (EAGLE) model, Gomes, Jacquinot, Mohr, and Pisani (2011) study the domestic and the cross-country effects of competition enhancing reforms occurring in Germany and Portugal and stress the benefits of cross-country coordinated policies. ${ }^{5}$

In this paper we focus on Italy which provides, as already stressed, a case study of an economy industrially advanced but ultimately failing to take off in sustained growth at rates above the EU 15 average and in urgent need of economic reforms. Notably, a slowdown in productivity was the key factor dragging down economic growth (see e.g. Codogno, 2009; OECD, 2011). In the decade 1997-2006 the average annual gross national income growth rate was $1.6 \%$ for Italy and $2.5 \%$ for EU 15. ${ }^{6}$ Turning to the labor market, according to EUROSTAT data, ${ }^{7}$ in 2009 Italy recorded an employment rate equal to $60.5 \%$ (against a $62.8 \%$ in 2007 before the advent of the crisis), Germany to $69.9 \%$ (73.4\% in 2007), France to $69.1 \%$ (69.5\% in 2007), Spain to $65 \%$ (62.5\% in 2007) with an EU 27 average employment rate of $67.7 \%$ (70\% in 2007). Hence, despite considerable progress made in the last decade, the employment rate is still significantly lower than the EU average. ${ }^{8}$ As regards to the tax burden on labor income, Italy stands out among the EU member states with the

\footnotetext{
${ }^{4}$ For an overview on the evolution of economic policy modeling from a theoretical and technical perspective see Ruiz Estrada and Yap (2012).

5 The DGE modeling approach has also been fruitfully used to examine the implications of tax reforms and/or alternative fiscal consolidation strategies (e.g. Heer \& Trede, 2003 for Germany, Papageorgiou, 2009 for Greece, Forni, Gerali, \& Pisani, 2010b and Marattin, Marzo, \& Zagaglia, 2011 for the EMU).

6 Annual growth rates computed on gross national income at 2000 market prices, see Annual macro-economic database (AMECO) - European Commission.

7 See EUROSTAT, Europe 2020 Indicators, Table t2020_10.

${ }^{8}$ Further, in 2009 the share of population at risk of poverty or social exclusion is found to be $24.7 \%$ for Italy, $20 \%$ for Germany, 18.4\% for France, 23.4\% for Spain and 23.1\% for EU 27. See Eurostat, Europe 2020 Indicators, Table t2020_50.
} 
largest implicit tax rate on labor (in $200842.8 \%$ against $36.5 \%$ for EU 27). ${ }^{9}$ Furthermore, in 2006 the gross domestic expenditure on R\&D was just $1.1 \%$ of GDP, well below the EU 27 share of $1.9 \% .{ }^{10}$ Finally, as already stressed, the very high public debt (in 2011 the debt-to-GDP ratio is $120.5 \%^{11}$ ) and the related-debt servicing costs continue to weigh on the Italian economy. Clearly, all these features of the Italian economy together with the contingent situation and the credibility crisis, call for the immediate implementation of a sizeable fiscal consolidation package and of economic reforms able to relaunch growth, foster social inclusion, favor the full utilization of the economy labor potential and promote a business friendly environment.

In what follows we will explore the potential macroeconomic impact of several provisions in the spirit of the reform packages currently being undertaken or debated. More precisely, our analysis covers two wide policy areas of intervention: (i) liberalization and simplification; (ii) labor market. ${ }^{12}$

The first policy area includes reform packages focusing on promoting market competition and favoring business, comprises a set of measures aimed at easing the Italian bureaucracy and reduce the administrative burden. The second policy area refers to labor market reforms including measures directed to enlarge the labor force participation rate, to expand social inclusion of low income and low skilled people, to remove distortions in the labor markets and to align wages to labor productivity trends.

In order to fully exploit the advantages of a micro-founded model, we analyze the implications of the economic reform packages on the main macrovariables and the dynamic interactions of reforms in each area of policy intervention by introducing simultaneously all changes to the policy variables. In fact, although we are not able to simulate all types of provisions envisaged in the reform packages for the two areas of interventions, by using a DGE model, we can verify the existence of interlinkages and synergies between different policy areas.

Finally, to complete the analysis, we will also consider comprehensive reform scenarios also embedding a fiscal consolidation package equivalent to $6 \%$ of the GDP necessary to lead the debt ratio toward a steadily declining path.

We find the following results. We show that all reforms mainly materialize in the short run bringing about sizable gains in output, consumption and employment and that most of these gains derive from labor market reforms. The positive effects on output and the improvement in employment support fiscal consolidation decreasing the public debt-to-GDP ratio also in the ex ante budget neutral scenarios.

The average annual output growth rate gain in ten-year time horizon is found to be equal to $0.6 \%$ under the assumption that Italy will manage to close half of the gaps toward the EU best performers in several areas of interventions in five years. Closing one third of the gaps would imply an average annual gain of $0.4 \%$, while closing fully the gap would increase average growth up to $1 \%$. However, the beneficial effects of the pro-competitive and business friendly interventions on the main macroeconomic variables are substantially reduced by the fiscal consolidation package. In such circumstances, consumption of the liquidity constraint households is likely to experience a strong decrease during the first years of the implementation of the reforms.

\footnotetext{
9 See Eurostat, Government finance statistics, Table gov_a_tax_itr.

10 See Eurostat, Europe 2020 Indicators, Table t2020_20.

11 See European Commission, General Government Data.

12 The first policy area of interventions refer to the so called "Liberalization" and "Simplification" Decree Law nos. 1 and 5 of January 2012. Reforms in the labor markets are currently debated and the policy agenda is still to be designed and agreed.
} 
The remainder of the paper is organized as follows. Section 2 is devoted to a brief description of QUEST III with R\&D and discusses the calibration of the version adapted to Italy. Section 3 describes the measures in the three policy areas under analysis with particular attention to the reform scenarios to be simulated and to the strategy adopted to map policy interventions onto QUEST. Section 4 explores and discusses the potential impact of structural reforms through simulation analysis. Section 5 concludes.

\section{QUEST III with R\&D: model setup and calibration}

In the version of QUEST III used in the present analysis the economy is confined to Italy, modeled as a small open economy. QUEST III with R\&D enriches the QUEST III DGE model described in Ratto et al. (2009) by incorporating an endogenous growth mechanism (see Roeger et al., 2008 for details) in the spirit of Jones (1995, 2005) and adapting the Romer (1990) model with R\&D.

By modeling final and intermediate goods markets as imperfectly competitive and by embodying entry and administrative burden costs, the model can be used to assess the effects of competition-enhancing policy and of administrative simplification interventions. Similarly, given the distinction of employment in three skill categories (low, medium, high), the inclusion of benefit replacement rates, labor taxes and of imperfect competition, it is possible to fruitfully study the implications of many labor market reforms. The model features eight types of economic agents: households-workers, trade unions, final goods firms, intermediate goods firms, R\&D sector, foreign sector, the government and the central bank. Adjustment costs on nominal and real variables enable QUEST to capture the typical persistence of macrovariables and mimic their empirical dynamics in response to shocks.

In what follows we describe the main features of QUEST, emphasizing the key ingredients and describing the policy variables to be used in our simulation exercise.

\subsection{Households and wage setting}

The economy is populated by two types of households: the non liquidity constrained and the liquidity constrained. The composition of the population is constant and the shares of liquidity and non liquidity constrained households are denoted by $s_{L C}$ and $s_{N L C}$, respectively. The non liquidity constrained households own domestic and foreign assets, accumulate physical capital which they rent out to the intermediate goods producers, buy the patents produced in the R\&D sector and license them to the intermediate goods sector, supply medium and high skilled labor services to the final goods sector and to the $\mathrm{R} \& \mathrm{D}$ sector, choose the optimal consumption plan on the basis of all the available information and taking into account all technological, institutional and budgetary constraints of the economy. The population shares of low, medium and high skilled are, respectively, denoted by $s_{L}, s_{M}$ and $s_{H}$. Policy aimed at achieving a skill upgrade of the labor force would imply changes in these shares.

The liquidity constrained households, instead, do not have access to financial markets hence, consume all their after tax labor income (i.e. they are not able to smooth consumption) and only supply low skilled labor services to the final goods sector (see Roeger et al., 2008). This feature of the model allows to deviate from Ricardian equivalence and is relevant to reproduce empirically consistent effects of fiscal policy (see e.g. Galí \& Gertler, 2007 for details). 
Within each skill category (high, $H$, medium, $M$, and low, $L$ ) households supply differentiated labor services. Trade unions set wages in monopolistically competitive labor markets, while nominal wage rigidities are due to the existence of convex adjustment costs for changing wages.

The representative non liquidity constrained household $i$ lifetime utility is

$$
V_{0}^{i}=E_{0} \sum_{t=0}^{\infty} \beta^{t}\left[U\left(C_{t}^{i}, C_{t-1}\right)+\sum_{s} V\left(1-L_{t}^{i, s}\right)\right]
$$

where $E_{0}$ is the conditional expectation operator (on the basis of the information available at $t=0), \beta$ is the discount factor, $U(\cdot)=(1-h a b c) \log \left(C_{t}^{i}-h a b c C_{t-1}\right)$ with $h a b c>0$ being the critical parameter governing habit persistence, $C_{t}^{i}$ a consumption basket (index) of domestic and foreign goods with constant elasticity of substitution, which determines the market power of each producer and the price markup, and $C_{t-1}$ the past level of the economy average consumption representing the stock of habit. In this sense habits are external to the individual household. $L_{t}^{i, s}$ denotes the typical labor service of household $i$ belonging to the skill category $s=H, M$ and $V(\cdot)=\omega_{s}\left(1-L_{t}^{i, s}\right)^{1-\kappa} /(1-\kappa)$ with $\omega_{s}>0$ being a skill specific preference parameter and $\kappa>0$.

Non liquidity constrained households decide how much to consume, how much to work, how much to invest in financial assets (domestic and foreign assets, labeled as $B_{t}^{i}$ and $B_{t}^{F, i}$ ) and in physical capital $K_{t}^{i}$, and make decisions about the purchase of new patents (the so called intangible capital $A_{t}^{i}$ ) and the degree of capacity utilization in order to maximize (1), subject to a sequence of flow budget constraints, the accumulation equations of physical capital and of the stock of existing patents and the standard transversality conditions.

Households receive labor income, profits from the final and the intermediate goods firms, transfers from the government, are eligible for benefits when unemployed and pay lump-sum taxes, consumption taxes, wage income taxes and capital income taxes on tangible and intangible capital (at rates $t^{K}, t^{A}$ ), less depreciation allowances and tax credits (at rates $\tau^{K}, \tau^{A}$ ). Finally, households face quadratic adjustment costs on investments in physical capital, on capacity utilization and on nominal wage changes (for more details, see Roeger et al., 2008).

Trade unions set the nominal wage for each category of labor service in order to maximize households' expected utility, given firms' labor demand. Each specific kind of labor service is an imperfect substitute for services supplied by other workers under the assumption of a constant elasticity of substitution which determines the degree of market power: the lower the elasticity of substitution, the higher the markup and the lower the employment level. Notice that the presence of tax on labor, unemployment benefits and consumption taxes together with the wage markup introduce a wedge between the real wage rate and the marginal rate of substitution between leisure and consumption, $M R S_{t, C, 1-L}$, that is

$$
\frac{W_{t}^{s}}{P_{t}^{C}}=\mathbf{M} \mathbf{U}_{W^{s}} \frac{1+t^{C}}{1-t^{w, s}-b^{s}} M R S_{t, C, 1-L}
$$

where index $s=L, M, H$ denotes the skill level, $W_{t}^{s}$ the nominal wage, $P_{t}^{C}$ the consumption price index, $\mathbf{M U}_{W^{s}}$ denotes the gross wage markup, $t^{C}$ the consumption tax rate, $t^{w, s}$ wage income tax rate and $b^{s}$ the unemployment benefit rate. As we will see, reforms intervening in the labor market and aimed at increasing the employment rate tend to reduce this wedge. 


\subsection{Final goods sector}

In the final goods sector each product $j$ is made by a monopolistic firm facing a demand function with price elasticity equal to $\sigma_{d}$, which is also the elasticity of substitution between different products and determines the degree of market power in the final goods sector.

The typical firm $j$ faces the following technology:

$$
Y_{t}^{j}=\left[A^{\operatorname{exog}}\left(L_{Y, t}^{j}-F C_{L}\right)\right]^{\alpha}\left[\sum_{i=1}^{A_{t}}\left(x_{i, t}^{j}\right)^{\theta}\right]^{(1-\alpha) / \theta} K G_{t}^{1-\alpha_{G}}-F C_{Y}, \quad \theta, \alpha, \alpha_{G} \in(0,1),
$$

where $Y_{t}^{j}$ is the final output, $A^{\text {exog }}$ is labor productivity, $L_{Y, t}^{j}$ is a CES combination of labor services with different skills, $F C_{L}$ denotes the so called overhead labor which captures the notion that a firm must employ a minimum amount of labor to produce any output at all (this includes hours spent on administrative tasks and bureaucracy as well as supervisory labor, breaks, meetings etc); $A_{t}$ is the number of varieties of intermediate inputs $x_{i, t}^{j}$ which are imperfect substitute with and an elasticity of substitution equal to $1 / \theta, K G_{t}$ is public capital whose level depends on the public infrastructure investment decisions $I_{t}^{G}$ and evolves as $K G_{t}=\left(1-\delta_{G}\right) K G_{t-1}+I_{t}^{G}$ with $\delta_{G}$ being the depreciation rate. Finally, $F C_{Y}$ is a fixed cost capturing a variety of institutional failures as well as the effort to enter the market. Measures to cut entry barriers are simulated by reducing this cost. The labor input $L_{Y, t}^{j}$ is defined by the following CES aggregator:

$$
\begin{aligned}
L_{Y, t}^{j}= & {\left[s_{L}^{1 / \sigma_{L}}\left(e f_{L} L_{t}^{L}\right)^{\left(\sigma_{L}-1\right) / \sigma_{L}}+s_{M}^{1 / \sigma_{L}}\left(e f_{M} L_{t}^{M}\right)^{\left(\sigma_{L}-1\right) / \sigma_{L}}\right.} \\
& \left.+s_{H, Y}^{1 / \sigma_{L}}\left(e f_{H} L_{t}^{H Y}\right)^{\left(\sigma_{L}-1\right) / \sigma_{L}}\right]^{\sigma_{L} /\left(\sigma_{L}-1\right)},
\end{aligned}
$$

where $s_{L}, s_{M}$ are the shares of labor force for low and medium skill categories and $s_{H, Y}$ denotes the share of high skilled workers employed in the final good sector. The coefficients $e f_{L}, e f_{M}$, $e f_{H}$ measure efficiency and $L_{t}^{L}, L_{t}^{M}, L_{t}^{H Y}$ the labor inputs for the three categories. Finally, the parameter $\sigma_{L}$ denotes the elasticity of substitution between the three skills (see Roeger et al., 2008).

The objective of each firm $j$ is to maximize profits by setting the optimal price $P_{t}^{j}$ and making choices about labor inputs and intermediate goods, given quadratic adjustment costs on price resetting (i.e. nominal frictions à la Rotemberg, 1982) and quadratic adjustment costs on employment changes (i.e. real frictions). Imperfect competition in the final goods market reflects on prices which will be equal to a markup, denoted as $\mathbf{M} \mathbf{U}_{P}$, over marginal costs. Pro-competitive policy interventions in the product market will be introduced into the model by decreasing this markup.

\subsection{Intermediate goods sector and the $R \& D$ sector}

The intermediate goods sector is also characterized by the presence of monopolistically competitive firms, indexed by $i$ (for $i=1, \ldots, A$ ), producing different varieties of the intermediate good $x_{t}$ employing physical capital $k_{t}$, rented from households at a rental rate $i_{t}^{k}$. The technology is linear and is such that to produce one unit of $x_{t}$ is necessary to employ one unit of physical capital. In order to enter the market and starts to produce, intermediate goods firms must license a patent from the households at a rate $i_{t}^{A}$, and pay a fixed cost equal to $F C_{A}$. The optimal price set by firm $i$ will be equal to a markup over, denoted as $\mathbf{M} \mathbf{U}_{P X}$, marginal cost. See Roeger et al. 
(2008) for further details. As in the final goods sector, structural policies aimed at cutting entry barriers can be simulated by reducing $F C_{A}$, while pro-competitive interventions are introduced through markup reduction.

The number of available intermediates goods depend on the number of patents created in the economy (i.e. the stock of knowledge), which, in turn, depends on the R\&D activity. In particular, in the R\&D sector the production of new patents depends on the number of high skilled workers employed, $L_{t}^{R D}$, and on the domestic and the international aggregate stocks of knowledge (labeled as $A$ and $A^{*}$, respectively), measured as the existing stock of patents. The knowledge production function is of the form:

$$
\Delta A_{t}=v A_{t-1}^{* \omega} A_{t-1}^{\varphi}\left(L_{t}^{R D}\right)^{\lambda}, \quad \omega, \varphi, \lambda \in(0,1),
$$

where $v>0$ is a measure of total productivity, $\omega$ and $\varphi$ capture the international and the domestic spillover effects of existing knowledge (the so called standing on shoulders effect) and $\lambda$ measures the contribution of high-skilled labor services to the R\&D activity (where decreasing returns of research activity is due to a sort of stepping on toes effect related to the risk of duplication of new discoveries and creations). This sector is also characterized by real frictions, deriving from the existence of quadratic costs on labor inputs adjustments.

\subsection{Foreign sector, monetary and fiscal authorities}

The foreign sector is completely exogenous since the model is developed under a small open economy hypothesis. It is assumed that both final and investment goods are traded and that the elasticity of substitution between domestic and foreign bundles of goods is constant. Importers and exporters act as monopolistic competitors in their market and charge a markup over domestic prices.

The monetary policy is described by a Taylor rule allowing for a certain degree of inertia of

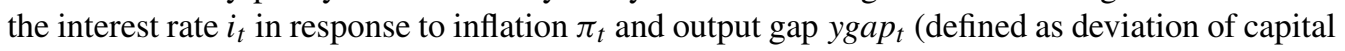
and labor utilization from their long-run trends):

$$
i_{t}=\tau_{l a g} i_{t-1}+\left(1-\tau_{l a g}\right)\left[r^{e q}+\pi_{t}^{T}+\tau_{\pi}\left(\pi_{t}-\pi_{t}^{T}\right)+\tau_{y} y g a p_{t}\right],
$$

where $r^{e q}$ is the long-run real interest rate, $\pi_{t}^{T}$ is the inflation target, $\tau_{\text {lag }}$ is the smoothing parameter, while $\tau_{\pi}, \tau_{y}$ are the policy parameters governing the reaction to inflation and to output gap movements.

The fiscal authority behavior is described by a set of equations according to which expenditures and receipts also depend on economic fluctuations. The government collects lump-sum taxes, $T^{L S}$, taxes on labor income, on consumption and on tangible and intangible capital, net of tax credits and tax allowances, pays transfers and unemployment benefits to households, confers wage benefits to the R\&D firms and decides on public consumption, $G_{t}$, and public investment spending $I_{t}^{G}$ and may issue public debt bonds to finance current imbalances. The government budget constraint reads as:

$$
B_{t}=\left(1+i_{t}\right) B_{t-1}+P_{t}^{C} G_{t}+P_{t}^{C} I_{t}^{G}+T R_{t}+B E N_{t}+S_{t}-R_{t}^{G}-T_{t}{ }^{L S},
$$

where $B_{t}$ denotes government bonds, $P_{t}^{C}$ the consumption price index, while $T R_{t}, B E N_{t}$ and $S_{t}$ denote, respectively, transfers to households, unemployment benefits, total subsidies to tangible 
and intangible capital in the form of tax credit and depreciation allowances. Finally, $R_{t}^{G}$ is total tax revenues. ${ }^{13}$

\subsection{Calibration}

The QUEST III model is calibrated on quarterly basis in order to match steady-state ratios and specific features of the Italian economy in 2007 and consistently with the estimates of the basic QUEST III model (see Ratto et al., 2009). The parametrization is summarized in Table 1 (see D'Auria et al., 2009). As a benchmark, we also present the basic parametrization of QUEST III for the EU, as reported in Roeger et al. (2008) and in Roeger and in't Veld (2009, 2010). This extra piece of information is useful to understand how some country-specific economic features of Italy are mapped into the Italian version of the QUEST model with respect to the EU version.

Labor skill categories are defined so that low skilled workers are those with up to lower secondary education, high skilled workers are those with a tertiary education in science and technology, while medium skilled workers are defined residually. The skill distribution of the labor force in QUEST - Italy points to a high share of low skilled $s_{L}$ who represent $50 \%$ of the labor force and to a very low share of high skilled, $s_{H}=3 \%$. Unskilled labor is only supplied by liquidity constrained individuals, hence $s_{L C}=s_{L}$. It is worth mentioning that in QUEST III calibrated to the EU $s_{L C}=s_{L}=35 \%$ and $s_{H}=6 \%$.

The employment rate is set at $63 \%$, below the EU counterpart of $69 \%$, consistently with data. The employment level of the low skilled is only $52 \%$, well below the rate of the high skilled equal to $81 \%$. The skill premium of high skilled versus medium skilled is set at $37 \%$, well below the calibrated level for the EU of 50\%, implying that skilled workers appear not to take advantage of attaining high education level. The elasticity of substitution between pairs of labor inputs is equal to 1.22 in QUEST Italy, signaling a high degree of market power of labor market insiders (i.e. a high wage markup).

The final goods sector, employing labor and intermediate goods as inputs, is identified as the services sector, while the intermediate goods sector, which is capital and R\&D intensive, is identified as the manufacturing sector. ${ }^{14}$ Net markups present more than $20 \%$ in the final goods sector, about two times the one reported for the intermediate goods sector. This is consistent with the fact that markups in services tend to be higher than in manufacturing (see Christopoulou \& Vermeulen, 2008). The high fixed entry costs, $F C_{A}$ and $F C_{Y}$ set for the Italian version of QUEST emphasizes the cumbersome regulation borne by firms before they are able to operate legally which represents a significant bottleneck to productivity growth and capital accumulation. ${ }^{15}$

The R\&D sector is calibrated so as to highlight the weaknesses of the Italian economy in the knowledge creation process. In particular, the contribution of R\&D labor to knowledge creation,

\footnotetext{
13 By assumption, to ensure fiscal solvency and avoid any explosive behavior of public debt, the lump-sum component of taxation evolves as a function of the deviation of the debt-GDP ratio from a target level $b^{T}$ and of the current deficit (for more details see Roeger et al., 2008): $\Delta T_{t}^{L S}=\tau^{B}\left(\left(B_{t-1} / Y_{t-1} P_{t-1}\right)-b^{T}\right)+\tau^{D E F} \Delta\left(B_{t} / Y_{t} P_{t}\right)$, where $\tau^{B}$ and $\tau^{D E F}$ are policy parameters. In our simulations, however, we will switch off the rule for 20 years in order to isolate the effects deriving from the implementation of economic reforms from those implied by the automatic adjustment of lump-sum taxation implied by the fiscal rule.

${ }^{14}$ For further details on the calibration strategy adopted for QUEST, see Roeger et al. (2008) and D'Auria et al. (2009).

15 According to Djankov, La Porta, Lopez-De-Silanes, and Shleifer (2002) in Italy the completion of the 11 procedures required to start-up a firm takes up 121 business days.
} 
Table 1

QUEST III with R\&D - calibration for Italy and the EU.

\begin{tabular}{|c|c|c|c|}
\hline & Italy & $\mathrm{EU}$ & Source \\
\hline \multicolumn{4}{|l|}{ Households and labor market } \\
\hline Share of liquidity constrained $s_{L C}$ & 0.5 & 0.35 & EUROSTAT \\
\hline Share of non liquidity constrained $s_{N L C}$ & 0.5 & 0.65 & EUROSTAT \\
\hline Habit persistence on consumption $h a b c$ & 0.7 & 0.7 & QUEST3/estimates \\
\hline Preference parameter on leisure $\kappa$ & 5 & 4 & Calibration \\
\hline Population share of low-skilled $s_{L}$ & 0.5 & 0.35 & EUROSTAT \\
\hline Population share of medium-skilled $s_{\mathrm{M}}$ & 0.47 & 0.59 & EUROSTAT \\
\hline Population share of high-skilled $s_{H}$ & 0.03 & 0.06 & EUROSTAT \\
\hline Employment, low skilled $L_{L}$ & 0.52 & 0.57 & EUROSTAT \\
\hline Employment, medium skilled $L_{M}$ & 0.74 & 0.74 & EUROSTAT \\
\hline Employment, high skilled $L_{H}$ & 0.81 & 0.84 & EUROSTAT \\
\hline Employment rate $L$ & 0.63 & 0.69 & EUROSTAT \\
\hline Skill elasticity of substitution $\sigma_{L}$ & 2 & 1.4 & Katz and Murphy (1992) \\
\hline Wage premium, high v. medium (\%) & 37 & 50 & EUROSTAT \\
\hline Wage premium, medium v. low (\%) & 27 & 24 & EUROSTAT \\
\hline Benefit replacement rate & 0.4 & 0.4 & Estimates \\
\hline \multicolumn{4}{|l|}{ Final and intermediate goods sectors } \\
\hline Net markup (\%), final $\mathbf{M} \mathbf{U}_{P}-1$ & 21 & 24 & EUKLEMS \\
\hline Net markup (\%), intermediate $\mathbf{M} \mathbf{U}_{P X}-1$ & 10 & 12 & EUKLEMS \\
\hline Depreciation rate, tangible capital $\delta_{K}(\%)$ & 1.5 & 1.5 & Calibration \\
\hline Fixed entry costs, final, $F C_{Y}$ & 0.15 & 0.10 & Calibration \\
\hline Fixed entry costs, intermediate, $F C_{A}$ & 0.45 & 0.38 & Djankov et al. (2002) \\
\hline Overhead labor $(\%), F C_{L}$ & 1.17 & 3.94 & Calibration \\
\hline \multicolumn{4}{|l|}{$\mathrm{R} \& \mathrm{D}$ sector } \\
\hline Elasticity of R\&D wrt labor $\lambda$ & 0.37 & 0.73 & Bottazzi and Peri (2007) \\
\hline Elasticity of R\&D wrt domestic ideas $\varphi$ & 0.64 & 0.53 & Bottazzi and Peri (2007) \\
\hline Elasticity of R\&D wrt foreign ideas $\varpi$ & 0.34 & 0.45 & Bottazzi and Peri (2007) \\
\hline $\mathrm{R} \& \mathrm{D}$ efficiency $v$ & 0.2 & 0.35 & Calibration - implied \\
\hline \multicolumn{4}{|l|}{ Taxes, public spending and public debt } \\
\hline Labor tax $t^{L}(\%)$ & 51 & 34 & Calibration \\
\hline Tax rate on tangible capital income $t^{K}(\%)$ & 33 & 45 & Warda (2006) \\
\hline Consumption $\operatorname{tax} t^{C}(\%)$ & 17 & 17 & $\mathrm{EC}$ \\
\hline Transfers (\%GDP) & 27 & 16 & EUROSTAT \\
\hline Government consumption (\% GDP) & 20 & 18 & Calibration \\
\hline
\end{tabular}

governed by the parameter $\lambda$, is only 0.37 (vs. 0.73 for the EU) and R\&D intensity is $1.10 \%$, below the EU level set at $1.84 \% .^{16}$

Finally, the tax system calibration points to heavy taxation on labor income (51\%) and a high share of transfers as a percentage of GDP (27\%), while the tax rate on tangible capital is below the rate set for the EU version of QUEST.

\footnotetext{
16 This result follows from the analysis by Bottazzi and Peri (2007) who estimate a production function of new ideas in the spirit of Jones $(1995,2002)$ and, accordingly, new ideas are produced by personnel employed in R\&D who use their creativity and the existing national and international stock of knowledge, as in Eq. (5).
} 


\section{The reform scenarios}

The simulation exercise quantifies the likely gains of implementing a set of provisions inspired to the reform packages being undertaken or presently under discussion. In this section will briefly describe the key policy areas of interventions, show how reforms are mapped onto QUEST III-Italy and describe the reform scenarios.

\subsection{Policy areas and QUEST III variables}

The first policy area of intervention, labeled liberalization and simplification, refers to all policies promoting competition in the manufacturing and in the services sectors and to measures aimed at reducing the administrative and regulatory burdens. In particular, we consider: (i) interventions improving competition and ameliorating the business environment in which firms operate, simply modeled as a reduction in the markup in the two relevant sectors, namely $\mathbf{M U}_{P}$, $\mathbf{M U}_{P X}$; (ii) reduction of barriers to economic activity, simulated as a reduction in fixed entry costs $F C_{Y}, F C_{A}$; (iii) improvement in the efficiency of public administration services, are introduced in QUEST by a decrease in $F C_{L}$ in Eq. (1) representing the fraction of time spent with government bureaucracy.

The second area of policy interventions labeled labor markets includes a set of policies aimed at increasing employment, favoring social inclusion and augmenting the participation rate such as: (i) tax reforms with the scope of reducing distortions in the labor market and providing more incentives to labor market participation, such as tax shifts from labor to consumption (i.e. from direct to indirect taxation); (ii) reforms aimed at reducing the bargaining power of insiders and align wages to productivity trends, which are simply mapped by increasing the elasticity of substitution between pairs of differentiated labor inputs so to reduce the wage markup $\mathbf{M} \mathbf{U}_{W^{s}}$. These interventions, in fact, tend to reduce the wedge between the real wage and the marginal rate of substitution between leisure and consumption (see Eq. (2)).

Finally, the fiscal consolidation package includes (i) a cut in transfers to households, as a way of mapping social security reforms and pensions cuts, $T R_{t}$; (ii) a reduction of public consumption, $G_{t}$; (iii) increase in consumption tax rate, $t^{C}$, to reproduce the increase in the value added tax and in the fuel excise tax; (iv) increase in labor income tax as a way of mapping the rise of the additional regional tax rate on labor income; (v) increase in tax rates on tangible capital, $t^{K}$, as a way of mapping the additional extraordinary tax for the repatriation/regularization of capital held abroad (i.e. the "tax shield" program envisaged by a 2009 law provision), the introduction of the new municipal property tax and the increase in the cadastral rental value of the residential property; (vi) an improvement in the public sector balance budget due to the increased revenues from measures aimed at reducing tax evasion, widen the tax base and curtail the black economy.

Most of the above interventions are likely to reduce and redistribute rents, inducing agents to adjust their choices in accordance with the new conditions. Notably, on the one hand, deviations from perfect competition in the product market create rents, on the other hand, non-competitive labor markets allow workers to participate in these rents. Therefore, internal market deregulation, which implies a lower markup over marginal costs, would tend to reduce the bargained wage rate. From this point of view, in some circumstances workers may oppose to labor market deregulation if this is not accompanied or anticipated by a corresponding product market deregulation. ${ }^{17}$ In this

\footnotetext{
17 On this debate, see Blanchard and Giavazzi (2003) and the paper by Commendatore and Kubin (2009) and references therein.
} 
theoretical exercise, however, in all scenarios we are considering a comprehensive reform package which is likely to have pervasive beneficial effects on productivity, firm entry and, ultimately, on employment, real wages and output. In this context, opposition to reforms could be the result of limited rationality and/or of a myopic planning horizon.

\subsection{Scenarios}

In order to quantify the effects of structural reforms in the two policy areas of interventions we build three reform scenarios differing in the degree of progress made. We also consider two additional reform scenarios embedding a fiscal austerity plan. The scenarios are intended to be illustrative and the assumptions of the degree of progress made in each policy area are to some extent arbitrary. In particular, in the simulations we consider: (i) a moderate reform ex-ante budgetneutral scenario in which it is assumed that Italy will manage to close the gap toward the EU best performers by $1 / 3$ and will implement a tax shift from labor to consumption of $0.05 \%$ of the GDP (Scenario A); (ii) a substantial reform ex-ante-budget-neutral scenario aimed at closing the gap by $1 / 2$ with a tax shift of $0.1 \%$ of the GDP (Scenario B); (iii) a radical reform ex-ante-budget-neutral scenario in which it is assumed that Italy will close completely the gap and perform a tax shift equal to $0.2 \%$ of the GDP (Scenario C); (iv) a moderate reform scenario including a fiscal consolidation package with a cumulative adjustment equivalent to $6 \%$ of the GDP (Scenario D); (v) a substantial reform scenario including a fiscal consolidation package with a cumulative adjustment equivalent to $6 \%$ of the GDP (Scenario E). All scenarios and the sizes of each intervention are described in Table 2.

The results obtained in the radical reform Scenario $\mathrm{C}$ need to be interpreted as a sort of ultimate upper bound of the potential effects of the structural reforms, since already Scenario B represents a decisive break from past policies and its implementation requires credible policy commitment and public consensus.

In the simulation exercise we suppose that at time $t=1$ the reform plan is announced and the policy measures start to be implemented phasing in gradually over five years. ${ }^{18}$ A period of five years represents, in fact, a realistic time span for a reasonably smooth implementation timetable. ${ }^{19}$ The fiscal consolidation package is instead introduced over a period of three years. Further, all policy changes are assumed to be permanent, as common practice in applied economic modeling when exploring the long-run effects of policy interventions. ${ }^{20}$ As will see in Section 4 , the effects of some reforms may take time to materialize and the gains may be diffuse and unevenly distributed.

The definition of two intervention areas provides a natural design for the simulation analysis. Reforms in each area are first simulated separately and then simultaneously in order to explore potential synergies. Finally, notice that agents have perfect foresight, so that there is no uncertainty

\footnotetext{
${ }^{18}$ We have also run simulations under the assumption that all changes take place immediately according to the so called big bang approach. Of course, the case of immediate implementation is expected to be an upper bound of the possible effects deriving from the reform plan. These results are available upon request.

19 Of course, a more gradual introduction of all reforms would allow to analyze the effects of a slower implementation motivated by the possible delays due to the need to form consensus for reforms to eventually occur. On the political economy of structural reforms debate about pros and cons of shock therapy versus gradualism see Rodrik (1996) and Wei (1997) among others.

${ }^{20}$ For details on the implementation strategy adopted in QUEST to solve the terminal conditions problem for the forward looking variables, see Roeger and in't Veld (1999).
} 
Table 2

Reform scenarios

\begin{tabular}{|c|c|c|c|c|c|c|}
\hline & & Scenario A & Scenario B & Scenario C & Scenario D & Scenario E \\
\hline \multirow[t]{5}{*}{$\begin{array}{l}\text { Liberalization and } \\
\text { simplification }\end{array}$} & $\begin{array}{l}\text { Reduce markup in the } \\
\text { intermediate goods } \\
\text { sectors }^{(1)}\end{array}$ & $0.3 p p$ & $0.5 \mathrm{pp}$ & $1 \mathrm{pp}$ & $0.3 p p$ & $0.5 \mathrm{pp}$ \\
\hline & $\begin{array}{l}\text { Reduce markup in the } \\
\text { final goods sector } \\
(1)\end{array}$ & $1.43 p p$ & $2.15 \mathrm{pp}$ & $4.3 \mathrm{pp}$ & $1.43 \mathrm{pp}$ & $2.15 \mathrm{pp}$ \\
\hline & $\begin{array}{l}\text { Reduce entry cost in the } \\
\text { services }^{(1)}\end{array}$ & $4.4 \%$ & $6.7 \%$ & $13.3 \%$ & $4.4 \%$ & $6.7 \%$ \\
\hline & $\begin{array}{l}\text { Reduce entry cost in } \\
\text { manufacturing } \\
(1)\end{array}$ & $12.6 \%$ & $18.9 \%$ & $37.8 \%$ & $12.6 \%$ & $18.9 \%$ \\
\hline & $\begin{array}{l}\text { Reduce administrative } \\
\text { burden }^{(1)}\end{array}$ & $1 \%$ & $1.7 \%$ & $3.4 \%$ & $1 \%$ & $1.7 \%$ \\
\hline \multirow[t]{8}{*}{ Labor market } & $\begin{array}{l}\text { Increase elasticity of } \\
\text { subst. between labor } \\
\text { inputs }^{(2)}\end{array}$ & $10.7 \%$ & $16.1 \%$ & $32.2 \%$ & $10.7 \%$ & $16.1 \%$ \\
\hline & $\begin{array}{l}\text { Tax shift from labor to } \\
\text { consumption }\end{array}$ & $0.05 \%$ of GDP & $0.1 \%$ of GDP & $0.2 \%$ of GDP & $0.05 \%$ of GDP & $0.1 \%$ of GDP \\
\hline & $\begin{array}{l}\text { Reduce public } \\
\text { consumption }\end{array}$ & $\cdots$ & $\ldots$ & $\ldots$ & $1.6 \%$ of GDP & $1.6 \%$ of GDP \\
\hline & $\begin{array}{l}\text { Reduce transfers to } \\
\text { households }\end{array}$ & $\cdots$ & $\cdots$ & $\ldots$ & $0.1 \%$ of GDP & $0.1 \%$ of GDP \\
\hline & Increase consumption tax & $\ldots$ & $\ldots$ & $\ldots$ & $1.5 \%$ of GDP & $1.5 \%$ of GDP \\
\hline & Increase labor tax & $\ldots$ & $\ldots$ & $\ldots$ & $1 \%$ of GDP & $1 \%$ of GDP \\
\hline & $\begin{array}{l}\text { Extra revenues from fight } \\
\text { against tax evasion }\end{array}$ & $\ldots$ & $\ldots$ & $\ldots$ & $0.3 \%$ of GDP & $0.3 \%$ of GDP \\
\hline & Increase tax on capital & $\ldots$ & $\ldots$ & $\ldots$ & $1.5 \%$ of GDP & $1.5 \%$ of GDP \\
\hline
\end{tabular}

Note: Degree of effort based on our elaboration of country variants of the QUEST III model: (1) gap reduction toward the EU15 best performers; (2) gap reduction toward the EU27 best performers. 
about the time path of the reforms. The implicit assumption is that the announced reform plans are fully credible.

\section{Simulation results}

In this section we illustrate the impact of all reforms embedded in Scenarios A and B showing the effect on the main macrovariables during the first 5 years and after 10 years. Then, we illustrate the economic implications of the implementation of the reforms under the fiscal austerity plan (i.e. Scenarios C and D).

\subsection{The macroeconomic effects of structural reforms}

Tables $3 \mathrm{a}$ and $3 \mathrm{~b}$ report the simulation results for key macroeconomic variables in the two scenarios of reforms, $\mathrm{A}$ and $\mathrm{B}$, as percentage deviations from the initial pre-reform steady-state.

In Table 3a we consider the effects of the reforms on output, investments on tangible capital and consumption, distinguishing between non liquidity constrained households (NLC) and liquidity constrained (LC) households, who represent the share of the population supplying only low skilled labor services and are at higher risk of poverty. Table $3 \mathrm{~b}$ presents the effects on total employment, real wages, public debt-to-GDP ratio, terms of trade and net foreign assets. Our interest on external variables, such as the net foreign assets position and the terms of trade, is to be related to the policy debate in the aftermath of the recent crisis. ${ }^{21}$

In particular, we observe that after 10 years structural reforms could help to boost output with respect to the initial steady state from $4.06 \%$ in the moderate reform Scenario A, up to $5.77 \%$ in the substantial reform Scenario B. Scenario C shows that there is much scope for growth up to a cumulated increase in output of $9.69 \%$. The major contribution is to be attributed to the policies intervening in the area of labor markets able to boost output up to $2.74 \%$ in scenario A and to $3.70 \%$ in scenario B. From Table $3 \mathrm{a}$ it clearly emerges that all reforms are likely to produce positive effects on output already in the short run.

Aggregate consumption would increase up to $2.44 \%$ and $3.35 \%$ (with a potential $5.25 \%$ ) after 10 years. Most of the gains accrue to the liquidity constrained households by virtue of the reforms improving the efficiency of the internal market. Notice that the major effort toward liberalization induces forward looking non liquidity constraint consumers to postpone their consumption decisions during the early phases of the reform process. Intuitively, agents find it optimal to save more during the early phase of the reform process so to maximize the expected future increase in output.

As expected, liberalization ad simplification measures boost investments significantly already during the first years.

Turning to employment, after 10 years the moderate reform Scenario A would imply an increase of $3.54 \%$, while the substantial reform Scenario B an increase of $4.78 \%$. In general, it can be noted that employment is strongly and positively affected by all the labor market interventions which have a direct impact on labor and supply schedules. Wage moderation pushes toward an alignment of wages to productivity trends and, at the same time, fiscal reforms aimed at narrowing the labor

\footnotetext{
${ }^{21}$ Recent developments during the crisis in Europe call for the need of broadening the surveillance in macroeconomic imbalances other than fiscal imbalances and of an early warning system to prevent future crises. Notably, the last crisis has shown how excessive external imbalances and losses in competitiveness in international markets have strongly reduced the resilience of some EU countries and of the Euro area as a whole. See European Commission (2010).
} 
Table 3a

Impact of structural reforms (\% deviations from the initial steady state).

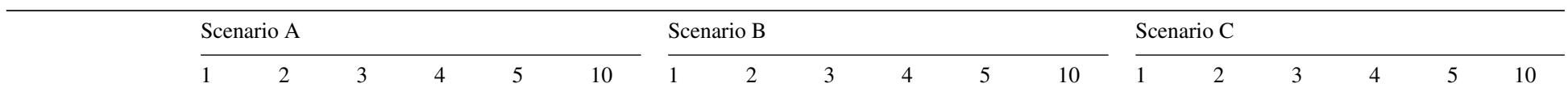

Output

Liberalization

(0.25)

and

simplification

Labor market

Sum of the

effects

Simultaneous

0.25

0.47

0.68

0.88

$0.69 \quad 1.18$

implementation

Consumption

$\begin{array}{lllllllllllllllllll}\text { Liberalization } & -0.12 & -0.11 & -0.01 & 0.11 & 0.22 & 0.45 & -0.21 & -0.20 & -0.04 & 0.14 & 0.31 & 0.67 & -0.44 & -0.45 & -0.14 & 0.21 & 0.54 & 1.23\end{array}$

and

simplification

Labor market

Sum of the

$\begin{array}{ll}0.94 & 1.65\end{array}$

$0.92 \quad 1$

$\begin{array}{lll}1.65 & 2.20 \quad 2.69\end{array}$

effects

Simultaneous

implementation

Consumption (NLC)

$\begin{array}{lllllllllllllllllllllll}\text { Liberalization } & -0.25 & -0.36 & -0.33 & -0.27 & -0.22 & -0.10 & -0.41 & -0.60 & -0.56 & -0.47 & -0.38 & -0.20 & -0.85 & -1.24 & -1.17 & -1.01 & -0.83 & -0.50\end{array}$

and

simplification

Labor market

Sum of the

$$
\begin{aligned}
& 0.95 \\
& 0.7
\end{aligned}
$$

$\begin{array}{llll}0.74 & 1.24 & 1.44 & 1.5\end{array}$

$0.62 \quad 1.13$

$0.60 \quad 1.10 \quad 1.40$

effects

Simultaneous

implementation

$\begin{array}{llllllllllllllllll}0.95 & 1.64 & 1.94 & 2.14 & 2.30 & 2.67 & 1.31 & 2.24 & 2.65 & 2.92 & 3.12 & 3.59 & 2.04 & 3.51 & 4.15 & 4.55 & 4.83 & 5.45 \\ 0.7 & 1.28 & 1.61 & 1.87 & 2.08 & 2.57 & 0.9 & 1.64 & 2.09 & 2.45 & 2.74 & 3.39 & 1.19 & 2.27 & 2.98 & 3.54 & 4 & 4.95 \\ 0.68 & 1.24 & 1.56 & 1.82 & 2.03 & 2.54 & 0.85 & 1.57 & 2.00 & 2.35 & 2.64 & 3.32 & 1.06 & 2.04 & 2.70 & 3.25 & 3.71 & 4.74\end{array}$


Table 3a (Continued)

\begin{tabular}{|c|c|c|c|c|c|c|c|c|c|c|c|c|c|c|c|c|c|c|}
\hline & \multicolumn{6}{|c|}{ Scenario A } & \multicolumn{6}{|c|}{ Scenario B } & \multicolumn{6}{|c|}{ Scenario C } \\
\hline & 1 & 2 & 3 & 4 & 5 & 10 & 1 & 2 & 3 & 4 & 5 & 10 & 1 & 2 & 3 & 4 & 5 & 10 \\
\hline \multicolumn{19}{|l|}{ Consumption (LC) } \\
\hline $\begin{array}{l}\text { Liberalization } \\
\text { and } \\
\text { simplification }\end{array}$ & 0.22 & 0.53 & 0.84 & 1.12 & 1.35 & 1.88 & 0.34 & 0.83 & 1.32 & 1.76 & 2.13 & 2.95 & 0.66 & 1.62 & 2.57 & 3.43 & 4.15 & 5.78 \\
\hline Labor market & 0.17 & 0.19 & 0.13 & 0.07 & 0.02 & 0.33 & 0.24 & 0.25 & 0.18 & 0.10 & 0.05 & 0.51 & 0.34 & 0.33 & 0.21 & 0.11 & 0.09 & 0.94 \\
\hline $\begin{array}{l}\text { Sum of the } \\
\text { effects }\end{array}$ & 0.39 & 0.72 & 0.97 & 1.19 & 1.37 & 2.21 & 0.58 & 1.08 & 1.5 & 1.86 & 2.18 & 3.46 & 1.0 & 1.95 & 2.78 & 3.54 & 4.24 & 6.72 \\
\hline $\begin{array}{l}\text { Simultaneous } \\
\text { implementation }\end{array}$ & 0.39 & 0.72 & 0.97 & 1.19 & 1.38 & 2.19 & 0.57 & 1.08 & 1.50 & 1.86 & 2.18 & 3.42 & 0.98 & 1.94 & 2.78 & 3.56 & 4.25 & 6.59 \\
\hline \multicolumn{19}{|l|}{ Investments } \\
\hline $\begin{array}{l}\text { Liberalization } \\
\text { and } \\
\text { simplification }\end{array}$ & 0.50 & 1.10 & 1.53 & 1.84 & 2.07 & 2.54 & 0.79 & 1.75 & 2.43 & 2.93 & 3.29 & 4.03 & 1.55 & 3.43 & 4.78 & 5.76 & 6.48 & 7.96 \\
\hline Labor market & 0.02 & 0.14 & 0.34 & 0.58 & 0.82 & 1.65 & 0.04 & 0.21 & 0.50 & 0.82 & 1.15 & 2.23 & 0.09 & 0.41 & 0.88 & 1.39 & 1.89 & 3.44 \\
\hline $\begin{array}{l}\text { Sum of the } \\
\text { effects }\end{array}$ & 0.52 & 1.24 & 1.87 & 2.42 & 2.89 & 4.19 & 0.83 & 1.96 & 2.93 & 3.75 & 4.44 & 6.26 & 1.64 & 3.84 & 5.66 & 7.15 & 8.37 & 11.4 \\
\hline $\begin{array}{l}\text { Simultaneous } \\
\text { implementation }\end{array}$ & 0.52 & 1.23 & 1.86 & 2.41 & 2.88 & 4.19 & 0.82 & 1.94 & 2.90 & 3.72 & 4.41 & 6.29 & 1.62 & 3.79 & 5.58 & 7.07 & 8.29 & 11.50 \\
\hline
\end{tabular}


Impact of structural reforms (\% deviations from the initial steady state).

\begin{tabular}{|c|c|c|c|c|c|c|c|c|c|c|c|c|c|c|c|c|c|c|}
\hline & \multicolumn{6}{|c|}{ Scenario A } & \multicolumn{6}{|c|}{ Scenario B } & \multicolumn{6}{|c|}{ Scenario C } \\
\hline & 1 & 2 & 3 & 4 & 5 & 10 & 1 & 2 & 3 & 4 & 5 & 10 & 1 & 2 & 3 & 4 & 5 & 10 \\
\hline \multicolumn{19}{|l|}{ Employment } \\
\hline Liberalization and simplification & 0.17 & 0.28 & 0.32 & 0.33 & 0.29 & 0.10 & 0.26 & 0.43 & 0.50 & 0.51 & 0.44 & 0.15 & 0.51 & 0.83 & 0.97 & 0.98 & 0.86 & 0.29 \\
\hline Labor market & 0.78 & 1.56 & 2.08 & 2.51 & 2.85 & 3.47 & 1.09 & 2.16 & 2.88 & 3.46 & 3.91 & 4.69 & 1.75 & 3.48 & 4.64 & 5.53 & 6.20 & 7.15 \\
\hline Sum of the effects & 1.0 & 1.8 & 2.4 & 2.8 & 3.1 & 3.6 & 1.35 & 2.59 & 3.38 & 3.97 & 4.35 & 4.84 & 2.26 & 4.31 & 5.61 & 6.51 & 7.06 & 7.44 \\
\hline Simultaneous implementation & 0.93 & 1.80 & 2.36 & 2.78 & 3.08 & 3.54 & 1.31 & 2.50 & 3.28 & 3.85 & 4.24 & 4.78 & 2.14 & 4.06 & 5.28 & 6.16 & 6.71 & 7.30 \\
\hline \multicolumn{19}{|l|}{ Real wages } \\
\hline Liberalization & 0.26 & 0.70 & 1.11 & 1.48 & 1.80 & 2.53 & 0.40 & 1.09 & 1.73 & 2.32 & 2.82 & 3.97 & 0.79 & 2.12 & 3.39 & 4.54 & 5.53 & 7.81 \\
\hline Labor market & -0.18 & -0.49 & -0.83 & -1.18 & -1.46 & -1.45 & -0.27 & -0.71 & -1.18 & -1.65 & -2.03 & -1.93 & -0.49 & -1.26 & -2.04 & -2.75 & -3.27 & -2.84 \\
\hline Sum of the effects & 0.08 & 0.21 & 0.28 & 0.3 & 0.34 & 1.08 & 0.13 & 0.38 & 0.55 & 0.67 & 0.79 & 2.04 & 0.30 & 0.86 & 1.35 & 1.79 & 2.26 & 4.97 \\
\hline Simultaneous implementation & 0.08 & 0.23 & 0.30 & 0.33 & 0.36 & 1.05 & 0.16 & 0.43 & 0.61 & 0.74 & 0.85 & 1.98 & 0.36 & 1.00 & 1.54 & 2.00 & 2.42 & 4.80 \\
\hline \multicolumn{19}{|l|}{ Terms of trade } \\
\hline Liberalization and simplification & -0.27 & -0.36 & -0.45 & -0.53 & -0.60 & -0.74 & -0.43 & -0.57 & -0.71 & -0.84 & -0.94 & -1.15 & -0.84 & -1.12 & -1.38 & -1.62 & -1.81 & -2.20 \\
\hline Labor market & -0.44 & -0.70 & -0.94 & -1.16 & -1.33 & -1.74 & -0.61 & -0.96 & -1.30 & -1.58 & -1.82 & -2.33 & -0.99 & -1.56 & -2.07 & -2.49 & -2.82 & -3.48 \\
\hline Sum of the effects & -0.71 & -1.06 & -1.39 & -1.69 & -1.93 & -2.48 & -1.04 & -1.53 & -2.01 & -2.42 & -2.76 & -3.48 & -1.83 & -2.68 & -3.45 & -4.11 & -4.63 & -5.68 \\
\hline Simultaneous implementation & -0.70 & -1.03 & -1.36 & -1.66 & -1.89 & -2.45 & -1.01 & -1.48 & -1.94 & -2.34 & -2.67 & -3.41 & -1.73 & -2.51 & -3.25 & -3.89 & -4.40 & -5.52 \\
\hline \multicolumn{19}{|l|}{ Net foreign assets (\% GDP) } \\
\hline Liberalization and simplification & 0.18 & 0.53 & 0.86 & 1.16 & 1.45 & 2.68 & 0.28 & 0.85 & 1.38 & 1.87 & 2.33 & 4.29 & 0.57 & 1.69 & 2.75 & 3.73 & 4.65 & 8.56 \\
\hline Labor market & 0.06 & 0.16 & 0.42 & 0.90 & 1.58 & 6.55 & 0.08 & 0.23 & 0.59 & 1.26 & 2.20 & 8.89 & 0.15 & 0.46 & 1.13 & 2.25 & 3.77 & 14.00 \\
\hline Sum of the effects & 0.24 & 0.69 & 1.28 & 2.06 & 3.03 & 9.23 & 0.36 & 1.08 & 1.97 & 3.13 & 4.53 & 13.18 & 0.72 & 2.15 & 3.88 & 5.98 & 8.42 & 22.56 \\
\hline Simultaneous implementation & 0.23 & 0.66 & 1.23 & 1.99 & 2.94 & 9.09 & 0.35 & 1.03 & 1.88 & 2.99 & 4.34 & 12.92 & 0.67 & 2.01 & 3.61 & 5.57 & 7.88 & 21.83 \\
\hline \multicolumn{19}{|l|}{ Public debt (\% GDP) } \\
\hline Liberalization and simplification & -0.25 & -0.50 & -0.86 & -1.28 & -1.75 & -4.36 & -0.39 & -0.78 & -1.34 & -2.01 & -2.74 & -6.83 & -0.74 & -1.49 & -2.56 & -3.85 & -5.26 & -13.21 \\
\hline Labor market & -0.75 & -1.33 & -1.81 & -2.28 & -2.75 & -5.43 & -1.03 & -1.81 & -2.46 & -3.08 & -3.69 & -7.20 & -1.63 & -2.81 & -3.76 & -4.67 & -5.55 & -10.66 \\
\hline Sum of the effects & -1.00 & -1.83 & -2.67 & -3.56 & -4.50 & -9.79 & -1.42 & -2.59 & -3.80 & -5.09 & -6.43 & -14.03 & -2.37 & -4.3 & -6.32 & -8.52 & -10.8 & -23.9 \\
\hline Simultaneous implementation & -0.98 & -1.80 & -2.62 & -3.52 & -4.45 & -9.74 & -1.38 & -2.52 & -3.71 & -4.98 & -6.32 & -13.93 & -2.25 & -4.10 & -6.07 & -8.24 & -10.52 & -23.64 \\
\hline
\end{tabular}


tax wedge, reduce fiscal distortions and deadweight losses due to the strong fiscal pressure on labor income. As a result of this, it is easy to explain how stronger efforts in this direction, coupled with the tax shift from direct to indirect taxation, can bring about higher employment rates and higher growth. All the remaining measures produce very small effects on employment, since in QUEST the labor market is characterized by strong rigidities (adjustment costs) which are responsible for the slow and costly adjustment of employment in response to shocks.

Aggregate real wages respond gradually. The net effect after ten years depend on how much ambitious the reform plan is. The very smoothed dynamics is due to the adjustment costs on wages and prices. It should be noted as in general we observe that the positive effects on real wages due to pro-competitive interventions tend to be compensated by the negative effects due to labor markets reforms. However, the net effect tends to be positive.

The Italian terms of trade deteriorate in response to the reforms. This effect is simply the result of a decline in the export prices as a consequence of higher competition in the domestic economy. The negative terms of trade effect tends to mitigate the positive effects on consumption and investments stemming from the reforms.

The net foreign assets position is significantly affected by the reforms only in the long run and the size of the effects depends on different types of opposing forces. Intuitively, the effect on the net external position will depend on how a policy intervention is likely to affect imports, exports, private and public savings, investments and capital flows. Internal market reforms enhancing competition through price moderation have a positive effect on the current account through higher exports, while, at the same time, those creating a more friendly business environment expand investments with a negative effect on the current account. Labor market reforms increase labor supply leading to a fall in the country's relative wage and prices and so boosting exports and improving the next external asset position. On the other hand, real wage reduction implies lower marginal costs for firms, so boosting investments and capital inflows so to produce a negative effect.

Consider now the impact of the reforms on public debt to GDP ratio. It can be observed that reforms reduce the public debt to GDP ratio with respect to the initial steady state. The improvement can be easily explained by the fact that the positive effects on employment and GDP start materializing already in the first years of the simulation time horizon, increasing the tax base and the tax collection during all the decade. As a result, by increasing GDP and tax revenues the reforms will favor fiscal consolidation.

Finally, we observe that effects of single policy area reforms are more or less additive, as a consequence of the linear nature of the simulation results due, in turn, to the fact, that single reforms only affect the equations describing a specific policy area.

\subsection{Structural reforms and fiscal consolidation}

In this section we look at the macroeconomic impact effects of different interventions in the internal market, through liberalization and simplification measures, and in the labor market, through wage moderation and tax policy, taking into account the implications of the strong fiscal consolidation package necessary to put the public finances back on track (i.e. Scenarios D and E in Table 2).

Table 4 shows how anticipated gradual implementation of the structural reforms affect the economy under a policy of tight fiscal consolidation (up to about $6 \%$ of GDP). All simulations 
Table 4

Impact of structural reforms under fiscal consolidation (\% deviations from the initial steady state).

\begin{tabular}{|c|c|c|c|c|c|c|c|c|c|c|c|c|}
\hline & \multicolumn{6}{|c|}{ Scenario D } & \multicolumn{6}{|c|}{ Scenario E } \\
\hline & 1 & 2 & 3 & 4 & 5 & 10 & 1 & 2 & 3 & 4 & 5 & 10 \\
\hline Output & 0.41 & -0.09 & 0.09 & 0.42 & 0.65 & 1.34 & 0.78 & 0.56 & 0.99 & 1.51 & 1.92 & 3.04 \\
\hline Consumption & -0.40 & -0.58 & -0.30 & -0.10 & 0.03 & 0.30 & -0.23 & -0.29 & 0.12 & 0.44 & 0.64 & 1.17 \\
\hline Consumption (NLC) & -0.02 & 0.19 & 0.52 & 0.74 & 0.82 & 0.94 & 0.13 & 0.47 & 0.90 & 1.20 & 1.38 & 1.67 \\
\hline Consumption (LC) & -1.33 & -2.66 & -2.47 & -2.24 & -2.09 & -1.35 & -1.15 & -2.30 & -1.94 & -1.57 & -1.29 & -0.14 \\
\hline Investments & -0.47 & -0.66 & -0.48 & -0.13 & 0.27 & 2.49 & -0.16 & 0.04 & 0.55 & 1.17 & 1.80 & 4.60 \\
\hline Employment & 0.22 & -0.14 & -0.13 & 0.07 & 0.25 & 0.74 & 0.57 & 0.52 & 0.74 & 1.09 & 1.35 & 1.94 \\
\hline Real wages & 0.45 & 1.09 & 1.42 & 1.57 & 1.63 & 1.98 & 0.52 & 1.32 & 1.77 & 2.00 & 2.14 & 2.88 \\
\hline Terms of trade & v1.68 & -2.09 & -2.34 & -2.48 & -2.57 & -2.53 & -1.98 & -2.51 & -2.89 & -3.13 & -3.31 & -3.45 \\
\hline Net foreign assets (\% GDP) & 1.85 & 6.65 & 12.72 & 19.18 & 25.84 & 60.72 & 1.96 & 7.01 & 13.35 & 20.13 & 27.17 & 64.44 \\
\hline Public debt (\% GDP) & -1.79 & -4.59 & -9.14 & -14.29 & -19.64 & -49.49 & -2.17 & -5.27 & -10.18 & $\mathrm{v} 15.70$ & -21.45 & -53.62 \\
\hline
\end{tabular}


have been carried out under the arbitrary assumption that tax rates gradually return to their initial steady state levels after 20 years. $^{22}$

As expected the ambitious fiscal austerity plan severely erodes the positive effects of the reforms and in the less ambitious scenario the economy undergoes a recession in the second year of intervention.

Consumption declines as a result of the increase in taxation on labor and consumption and of the reduction of public transfers. Also employment temporally declines in the moderate reform scenario as a consequence of the lower level of economic activity and of the higher taxation on labor. Investments would tend to be positive, but of course lower than in Scenarios A and $\mathrm{B}$, without fiscal consolidation. The lower effect is the direct consequence of the lower level of economic activity coupled with an increase in the tax rate on capital.

Furthermore, liquidity constrained households would incur transitional losses as a result of the cut in transfers and increase in taxes on consumption. The loss will be slowly absorbed in the following years.

Overall, as the result of the vigorous fiscal consolidation package the average output growth rate gain in ten-year time horizon reduces from $0.6 \%$ to $0.3 \%$ in the substantial reform scenario and from $0.4 \%$ to $0.1 \%$ in the moderate reform scenario.

\section{Conclusions}

In recent months, after a prolonged period of slow growth and a severe confidence crisis, Italy has embarked on an ambitious reform package aimed at increase supply potential, improving competitiveness, ensure fiscal sustainability and enhance confidence in government ability to service its debt. This paper takes stock of the recent provisions undertaken or still on the table and quantifies the potential effects on the Italian economy of different reform scenarios including a broad range of policy interventions and differing in the progress made in two policy areas: liberalization-simplification and labor markets.

According to the simulations, policies aimed to enhance competition in goods market, simplify bureaucracy, increase labor supply and align wages to productivity trends are likely to generate sizable gains in output, consumption and employment and net foreign assets position already during the earlier phases of the implementation, and that most of these gains derive from labor market reforms.

The positive effects on output and the improvement in employment are able to support fiscal consolidation also in the ex-ante budget neutral scenarios. As regards to the external imbalances, the external asset position improves as a result of the reforms which boost domestic competitiveness and increase exports.

However, the fiscal austerity plan is likely to severely reduce the positive effects of the interventions, especially during the first years of reform process. In particular, liquidity-constraint households may incur transitional losses in consumption. Overall, our results clearly show that a stronger progress in implementing structural reforms is crucial to rein in the slowdown in the economic activity and the fall in consumption due to the fiscal consolidation package.

Finally, some words of caution are needed since quantifying the impact of structural reforms on the main macrovariables is extremely difficult. First, all results have been generated through a

\footnotetext{
22 Of course, to have a more complete picture of the possible macroeconomic outcomes different time horizons for the duration of the austerity plan could be considered. Notably, in Italy the tax burden is already very high, that is why, sooner or later, measures designed to alleviate the fiscal burden will be needed.
} 
model, which, although built up with the purpose of evaluating the effects of structural reforms, only provides a stylized representation of an economy. The tight theoretical assumptions of QUEST, along with the fact that the degree of policy efforts considered in the paper are to some extent arbitrary, impose limitations which must be taken into consideration when interpreting the results. Second, the time lags in reforms implementation, the cross-country spillovers and complementarities, the trade-offs between reforms in different domains and the effects of shortterm economic fluctuations make it difficult to disentangle the effects of reforms undertaken from others determinants of performance. Third, we have assumed that the announced reform plans are fully credible and that agents have perfect foresight. However, there might be an initial lack of credibility and a problem of uncertainty about the effects of the reforms. Finally, the political economy interactions between product and labor market interventions are not considered here. The literature has shown that more competition in product markets may generate support for labor market deregulation, since lower rents in the goods markets reduces the incentives for trade unions to ask for higher rents when setting wages. From this point of view priority should be given to pro-competitive reforms in the product markets so as to create the required social consensus for labor and social protection reforms.

\section{References}

Annicchiarico, B., Di Dio, F., \& Felici, F. (2011). The macroeconomics of Europe 2020 reform strategy and the potential effects on the Italian economy, Working Papers no. 8, Department of the Treasury, Ministry of the Economy and of Finance.

Arpaia, A., Roeger, W., Varga, J., in't Veld, J., Hobza, A., Grilo, I., et al. (2007). Quantitative assessment of structural reforms: Modelling the Lisbon strategy, European Economy - Economic paper no. 282.

Bayoumi, T., Laxton, D., \& Pesenti, P. (2004). Benefits and spillovers of greater competition in Europe: A macroeconomic assessment, ECB Working Paper no. 341.

Blanchard, O. J., \& Giavazzi, F. (2003). Macroeconomic effects of regulation and deregulation in goods and labor markets. Quarterly Journal of Economics, 118(3), 879-909.

Bottazzi, L., \& Peri, G. (2007). The international dynamics of R\&D and innovation in the long run and in the short run. The Economic Journal, 117, 486-511.

Breuss, F., \& Roeger, W. (2005). The SGP fiscal rule in the case of sluggish growth: Simulations with the QUEST model. The Journal of Policy Modeling, 27, 767-788.

Christopoulou, R., \& Vermeulen, P. (2008). Markups in the Euro area and the US over the period 1981-2004: A comparison of 50 sectors, ECB Working Paper no. 856.

Codogno, L. (2009). Two Italian puzzles: Are productivity growth and competitiveness really so depressed? In M. Buti (Ed.), Italy in EMU - the challenges of adjustment and growth. London: Palgrave Macmillan.

Commendatore, P., \& Kubin, I. (2009). Dynamic effects of regulation and deregulation in goods and labour markets. Oxford Economic Papers, 61(3), 517-537.

Conte, A., Labat, A., Varga, J., \& Zarnic, Z. (2010). What is the growth potential of green innovation? An assessment of EU climate policy options, European Economy - Economic paper no. 413.

D’ Auria, F., Pagano, A., Ratto, M., \& Varga, J. (2009). A comparison of structural reform scenarios across the EU member States: Simulation-based analysis using the QUEST model with endogenous growth, European Economy - Economic Paper no. 392.

Djankov, S., La Porta, R., Lopez-De-Silanes, F., \& Shleifer, A. (2002). The regulation of entry. The Quarterly Journal of Economics, 117(1), 1-37.

European Commission (2010). Surveillance of Intra-Euro-Area competitiveness and imbalances, European Economy $1 / 2010$.

Everaert, L., \& Schule, W. (2006). Structural reforms in the Euro area: Economic impact and role of synchronization across markets and countries, IMF Working Paper no. 06/137.

Forni, L., Gerali, A., \& Pisani, M. (2010a). Macroeconomic effects of greater competition in the service sector: The case of Italy. Macroeconomic Dynamics, 14(5), 677-708. 
Forni, L., Gerali, A., \& Pisani, M. (2010b). The macroeconomics of fiscal consolidation in Euro area countries. Journal of Economic Dynamics and Control, 34(9).

Galí, J., \& Gertler, M. (2007). Macroeconomic modeling for monetary policy evaluation. Journal of Economic Perspectives, 21(4), 25-46.

Gomes, S., Jacquinot, P., Mohr, M., \& Pisani, M. (2011). Structural reforms and macroeconomics performance in the Euro area countries. A model-based assessment, ECB Working Paper no. 1323.

Heer, B., \& Trede, M. (2003). Efficiency and distribution effects of a revenue-neutral income tax reform. Journal of Macroeconomics, 25(1), 87-107.

Hobza, A., \& Mourre, G. (2010). Quantifying the potential macroeconomic effects of the Europe 2020 strategy: Stylised scenarios, European Economy - Economic Paper no. 424.

Issing, O. (2011). The crisis of European Monetary Union - Lessons to be drawn. Journal of Policy Modeling, 33(5), 737-749.

Jones, C. I. (1995). R\&D-based models of economic growth. Journal of Political Economy, 103(4), 759-784.

Jones, C. I. (2002). Sources of U.S. economic growth in a world of ideas. American Economic Review, 92(1), $220-239$.

Jones, C. I. (2005). Growth and ideas. In P. Aghion, \& S. Durlauf (Eds.), Handbook of economic growth (pp. 1063-1111). Amsterdam/New York/Oxford: Elsevier/North Holland.

Katz, L. F., \& Murphy, K. M. (1992). Changes in relative wages, 1963-1987: supply and demand factors. The Quarterly Journal of Economics, 107(1), 35-78.

Marattin, L., Marzo, M., \& Zagaglia, P. (2011). A welfare perspective on the fiscal-monetary policy mix: The role of alternative fiscal instruments. Journal of Policy Modeling, 33(6), 920-952.

OECD. (2011). Going for growth. Paris: OECD.

Papageorgiou, D. (2009). Macroeconomic implications of alternative tax regimes: The case of Greece, Bank of Greece Working Paper no. 97.

Ratto, M., Roeger, W., \& in't Veld, J. (2009). QUEST III: An estimated open-economy DSGE model of the Euro area with fiscal and monetary policy. Economic Modelling, 26(1), 222-233.

Roeger, W., \& in't Veld, J. (1999). The sensitivity of solutions to terminal conditions: Simulating permanent shocks with QUEST II. In J. Hughes Hallet, \& P. Mc Adam (Eds.), Analysis in macroeconomic modelling. Boston/Dordrecht/London: Kluver Academic Publishers.

Roeger, W., \& in't Veld, J. (2009). Fiscal policy with credit constraint households, European Economy - Economic Paper no. 357.

Roeger, W., \& in't Veld, J. (2010). Fiscal stimulus and exit strategies in the EU: A model-based analysis. European Economy - Economic Papers no. 426.

Roeger, W., Varga, J., \& in't Veld, J. (2008). Structural reforms in the EU: A simulation-based analysis using the QUEST model with endogenous growth, European Economy - Economic Paper no. 351.

Roeger, W., Varga, J., \& in't Veld, J. (2009). Modelling the Lisbon strategy: Analysing policies to promote knowledge investment with an endogenous growth model. Comparative Economic Studies, 51(4), 520-539.

Rodrik, D. (1996). Understanding economic policy reform. Journal of Economic Literature, XXXIV, 9-41.

Romer, P. (1990). Endogenous Technological Change. Journal of Political Economy, 98(5), 71-102.

Rotemberg, J. J. (1982). Sticky prices in the United States. Journal of Political Economy, 90(6), 1187-1211.

Ruiz Estrada, M. A., \& Yap, S. F. (2012). The origins and evolution of policy modeling. Journal of Policy Modeling, http://dx.doi.org/10.1016/j.jpolmod.2011.12.003

Smets, F., \& Wouters, R. (2003). An estimated stochastic dynamic general equilibrium model of the Euro area. Journal of the European Economic Association, 1(5), 1123-1175.

Smets, F., \& Wouters, R. (2007). Shocks and frictions in US Business cycles: A Bayesian DSGE approach. American Economic Review, 97(3), 586-606.

Warda, J. (2006). Tax treatment of business investments in intellectual assets: An international comparison, OECD Science, Technology and Industry Working Papers 2006/4, OECD.

Wei, S. J. (1997). Gradualism versus big bang: Speed and sustainability of reforms. The Canadian Journal of Economics, 30(4b), 1234-1247.

Woodford, M. (2003). Interest and prices. Princeton and Oxford: Princeton University Press. 